\title{
Impact of Including Quantitative Information in a Decision Aid for Colorectal Cancer Screening: A Randomized Controlled Trial
}

Running head: Including quantitative information in a decision aid

Peter H. Schwartz, MD, PhD ${ }^{a, b, c, d}$, Thomas F. Imperiale, MD ${ }^{a, e, f}$, Susan M. Perkins, PhD ${ }^{d, g}$, Karen K. Schmidt, MSN, RN, CCRPa, Sandra Althouse, $\mathrm{MA}^{\mathrm{g}}$, and Susan M. Rawl, PhD, RN, FAAN ${ }^{d, h}$

a. Department of Medicine, Indiana University School of Medicine, Indianapolis, USA

b. Indiana University Center for Bioethics, Indianapolis, USA

c. Philosophy Department, Indiana University, Indianapolis, USA

d. Indiana University Simon Cancer Center, Indianapolis, USA

e. Regenstrief Institute, Inc., Indianapolis, USA

f. Center of Excellence for Implementation of Evidence-based Practice, Roudebush VA Medical Center, Indianapolis, USA

g. Department of Biostatistics, Indiana University, Indianapolis, USA

h. Indiana University School of Nursing, Indianapolis, USA

\section{Corresponding author at:}

Peter H. Schwartz, MD, PhD

Indiana University Center for Bioethics

410 W. $10^{\text {th }}$ St., Ste. 3100

Indianapolis, IN 46202

USA

Telephone: 317-278-4037

Email: phschwar@iu.edu

Fax: 317-278-4050

Word count - Manuscript (text only): $\underline{3,965}$

Word count - Abstract: 200

Number of Tables: 5

Number of Figures: 1

Appendix: 2 tables and 2 figures

Trial Registration: ClinicalTrials.gov ID\# NCT02477553 
Highlights:

- First adequately powered, randomized, controlled trial of quantitative information in a decision aid.

- Viewing quantitative information did not reduce intention to be screened or uptake.

- Viewing quantitative information increased perceived risk of colorectal cancer.

- Viewing quantitative information increased selection of a non-invasive screening test.

\section{Abstract}

Objective: Guidelines recommend that decision aids provide quantitative information about risks and benefits of available options. Impact of providing this information is unknown.

Methods: Randomized trial comparing two decision aids about colorectal cancer (CRC) screening with colonoscopy or fecal immunochemical test (FIT). 688 primary care patients due for CRC screening viewed a decision aid that uses words only (Verbal arm) vs. one that provides quantitative information (Quantitative arm). Main outcomes included perceived CRC risk, intent to be screened, and test preference, measured before and after viewing decision aid, and screening uptake at six months. Analyses were performed with ANCOVA and logistic regression.

Results: Compared to the Verbal arm, those in the Quantitative arm had a larger increase in intent to undergo FIT ( $p=0.011)$ and were more likely to switch their preferred test from nonFIT to FIT ( $28 \%$ vs. $19 \%, p=.010)$. There were decreases in perceived risk in the Verbal Arm but not the Quantitative Arm ( $p=0.004)$. There was no difference in screening uptake. Numeracy did not mediate any effects.

Conclusions: Quantitative information had relatively minor impact and no clearly negative effects, such as reducing uptake.

Practice Implications: Quantitative information may be useful but not essential for patients viewing decision aids. 
Keywords: Informed decision making; Colorectal cancer screening; Decision aids; risk communication; numeracy

\section{Introduction}

Guidelines for the design of decision aids recommend disclosure of quantitative information such as, for screening tests, baseline risk of the condition, risk reduction provided by the intervention, positive and negative predictive values, and chance of negative outcomes $[1,2]$. Quantitative information may support informed decision making by increasing patient understanding $[3,4]$. Quantitative information may not help all patients, however, especially those with limited numeracy skills $[5,6]$. No well-powered randomized trial has measured the impact of disclosing the recommended types of quantitative information [7]. Heuristics and biases in human thought produce irrational responses to risk data including people's tendency to underestimate the risk of a bad outcome ("optimism bias") $[8,9]$. It would be unfortunate if disclosing quantitative information triggered heuristics or biases that reduced uptake of preventive measures that save lives [10-14].

In this study, we compared the effects of verbal information and quantitative information in a decision aid for colorectal cancer (CRC) screening. Screening is recommended for people ages 50-75 years old, and for those at average risk, several tests are recommended $[15,16]$. Colonoscopy is the most commonly performed screening test and provides the most complete examination of the colon, but it has risks and requires a rigorous bowel prep [15-17]. The second most common approach is annual stool blood testing, e.g. the fecal immunochemical test (FIT), which is easy to do and is performed at home [15-17]. A single application of FIT often fails to identify polyps and may miss a cancer, however, and a positive stool test requires colonoscopic evaluation. Lifetime risk reduction provided by regular FIT may be slightly less than that provided by regular colonoscopy, though there continues to be some uncertainty about the long-term effects $[15,18]$. The choice between colonoscopy, FIT, and other approved tests is "preference sensitive," resulting in the creation and testing of several decision aids [7].

The aims of the current study were to: 1) compare the impact of verbal information and quantitative information on outcomes of perceived CRC risk, CRC screening intent, colonoscopy 
intent, FIT intent, perceived benefits and barriers for colonoscopy and FIT, decision conflict, test choice (colonoscopy or FIT), and 6-month uptake of screening; and 2) determine whether numeracy moderates any of these effects.

\section{METHODS}

\subsection{Study Setting}

The study was conducted from June 2015 to June 2017 at 18 primary care sites in the Indiana University Health (IUH) and 6 primary care sites of the Eskenazi Health (EH) system in central Indiana. The study was approved by the Indiana University Institutional Review Board prior to data collection and is registered with ClinicalTrials.gov (NCT02477553).

\subsection{Inclusion and Exclusion Criteria}

Participants were screening-eligible male and female adults, 50-75 years old, who were scheduled or due to be seen by their primary care provider at participating clinics. Participants were eligible if they were not up-to-date with screening. We excluded patients who had: (1) a personal history of CRC, (2) inflammatory bowel disease or other condition or family history conferring elevated risk for CRC, (3) symptoms consistent with CRC, (4) difficulty reading English, or (5) been told by their provider to avoid CRC screening.

\subsection{Recruitment Process}

Physician approval was obtained prior to contacting patients who appeared to be eligible based on electronic health record (EHR) review. Of 80 physicians approached, 70 (88\%) agreed to have their patients contacted. Patients were sent an introductory letter and then contacted by phone to explain the study and assess eligibility. Eligible patients who agreed to participate met with a research assistant for approximately 1 hour, often immediately preceding a provider appointment.

\subsection{Study Procedure}


After confirming eligibility and providing written informed consent, participants were randomly assigned, using the REDCap database, to view the verbal decision aid (verbal group) or the quantitative decision aid (quantitative group). Stratification was based on age ( $\leq 65$ years old or $>65$ years old), gender (male, female), and health system.

Data were collected and managed using REDCap electronic data capture tools hosted at Indiana University [19]. Participants completed a baseline survey (T0) in REDCap using either a laptop computer or a paper version in the presence of a research assistant. They then viewed the decision aid to which they were assigned, and completed a self-administered survey postintervention (T1). Six months later, participants were contacted by phone to complete a third interview (data not presented in this paper), and participants' EHR data were checked for completion of a colonoscopy, FIT, or other approved screening test within six months of enrollment.

\subsection{Decision Aids}

Both decision aids consisted of PowerPoint slides with text, photos, and an audio track, viewed on a laptop controlled by the participant. The decision aids began with a $4 \frac{1}{2} \mathrm{~min}$ slightly edited version of a video on CRC screening produced by the American Cancer Society [20], followed by 3 slides summarizing the advantages and disadvantages of colonoscopy and stool testing with the fecal immunochemical test (FIT).

The quantitative decision aid explained the following quantitative information regarding CRC and the comparative effectiveness of colonoscopy and FIT, generally presented as frequencies depicted on icon charts:

- Sensitivity of a single application of FIT and colonoscopy for CRC,

- Average lifetime CRC incidence and mortality with no screening and with regular screening with colonoscopy or FIT (depicted individually on icon charts and jointly on a bar chart),

- Frequency of a single FIT turning positive, and

- Frequency of complication from a colonoscopy (hemorrhage or perforation). 
The verbal decision aid discussed each of these topics but used verbal descriptions only ("rare," "reduced," etc.) instead of numbers. Both decision aids used only verbal descriptions of the sensitivity of colonoscopy and FIT for polyps and the frequency of FIT yielding a false positive, i.e. negative colonoscopy after positive FIT. Appendix Table 1 lists the specific numbers and quantities disclosed in both decision aids. Decisions about which numbers to present and which terms to use in the decision aids were guided by recommendations from the International Patient Decision Aids Standards Collaboration (IPDAS) [1, 21] and discussions with the research team, patient advisory board, and community advisory board.

The decision aids were updated from versions used in a pilot study [22] by the research team that included experts in health communication, gastroenterology, epidemiology, risk communication, biostatistics, and bioethics. Scripts and visuals were circulated and discussed in biweekly meetings, and draft versions of the DAs were presented to patients and community members for assessment of acceptability, understandability, and satisfaction.

\subsection{Measures}

- Perceived Risk of CRC (T0, T1). Perceived personal risk of CRC was assessed by asking participants how likely they were to get colon cancer during their lifetime, in the next 10 years, and in the next 5 years. Each had response options: very likely, somewhat likely, somewhat unlikely, and very unlikely. Perceived comparative risk of CRC was measured with a single item assessing "compared to other women/men your same age, would you say your change of getting colon cancer in the next 10 years is higher, about the same, lower, or don't know."

- Benefits and Barriers (T0, T1). Perceived benefits and barriers were measured for colonoscopy and FIT separately using scales developed by our team [23]. All scales had Likert-type response options where $1=$ strongly agree to $5=$ strongly disagree.

- Screening Intent; FIT Intent; Colonoscopy Intent (T0, T1). Intent to be screened for CRC with any test ("Screening Intent"), intent to undergo FIT ("FIT Intent"), and intent to undergo colonoscopy ("Colonoscopy Intent") were measured with 3 separate items: "Do you plan to get a [colon test/ stool test/ colonoscopy] within the next 6 months?" Each had response 
options of: 5=Definitely, 4=Probably, 3=May or May not, 2=Probably not, and 1=Definitely not.

- Test Choice (T0, T1). For those who answered the Screening Intent question - "Do you plan to get a colon test within the next 6 months?" with Definitely not, Probably not, or May or may not, Test Choice was categorized as "No screening." Those who answered the Screening Intent question with Probably or Definitely had their Test Choice categorized based on their answer to a single item: "If you have a colon test, which one would you choose?" Response options were: FIT, Colonoscopy, Other, or Don't know.

- Decision Conflict (TO, T1). Decision conflict was assessed using the Decision Conflict Scale, a 16-item instrument [24].

- Numeracy. Subjective numeracy was assessed with the Subjective Numeracy Scale (SNS) at TO $[25,26]$. Objective numeracy was measured with the short 8-item Numeracy Understanding in Medicine Instrument (NUMi) at T1 [27, 28].

- Health Literacy (T1). Health literacy was assessed using a 3-item health literacy scale [29].

- Uptake. Screening uptake was determined by documentation of a completed screening test within 6 months of enrollment in the participants' EHR.

\subsection{Statistical Analysis:}

The sample size was based on results of our pilot study of a similar decision aid that showed overall CRC screening rates differed by $12 \%$ between the control and quantitative groups (26.9\% vs $39.3 \%$ ) [22]. To detect a similar difference in this study with $80 \%$ power with a chi-square test ( $\alpha=0.05$ ), a sample size of 241 per group (482 total) was required. To examine the moderating effect of numeracy, the required sample size was based on calculations provided in Demidenko (2008) [30] for detecting an interaction between two binary covariates (intervention group and numeracy) in a logistic regression model. In this case, a total of 600 (300 per group) were required to have $80 \%$ power ( $\alpha=0.05)$ to detect an interaction OR of 3.2, which was similar to the interaction OR estimated from our preliminary data of 3.7. Thus, to have sufficient power for both aims, targeted enrollment was 600 patients. 
All analyses were conducted using SAS Version 9.4 (Cary, NC) and the significance level set to $\alpha=0.05$ for all statistical tests. Demographic information was summarized by frequencies and percents for categorical variables or by mean and standard deviation (SD) for continuous variables. Group differences for categorical variables were compared with the Chi Square test or Fisher's Exact test. Continuous variables were compared using two-sample ttests.

All models included covariates for site (Eskenazi or IU), gender and age $(<=65$ years and $>65$ years) [31]. For aim 1, changes in perceived risk, screening intent, colonoscopy intent, FIT intent, benefits and barriers of colonoscopy and FIT, and decision conflict from baseline (T0) to post-intervention (T1) were compared between groups using ANCOVA with baseline scores treated as covariates. To check for changes in scores over time (i.e., assuming no interactions or main effects for group or numeracy), an intercept only model was used. Test choice was examined before and after intervention to see if there was a change in 1) intent to be screened (Test Choice $=$ No screening vs. Screening (with FIT, colonoscopy, other, or don't know); and 2) Test Choice of something other than FIT at TO (no screening, colonoscopy, other, or don't know) to FIT at T1 and tested between groups using logistic regression. CRC screening rates were compared between the two groups using logistic regression.

For aim 2, subjects were divided into two groups (above and below the median for total subjective numeracy and also for objective numeracy). First, moderation was tested by adding a main effect for numeracy and group by numeracy interaction term to the models used in aim 1. If the interaction term was not significant, it was removed from the model and the main effects model was used.

\section{Results:}

A total of 728 patients were randomized to quantitative $(n=364)$ or verbal $(n=364)$ groups (Figure 1). Forty patients were later excluded, resulting in sample sizes of 344 in each group. Mean age was 59 [s.d.=7] years. Most participants were white and 60\% were female. Except for employment status, there were no statistically significant differences in demographic variables between the groups (Table 1). Thus, employment status was a covariate in models. 


\subsection{Perceived Risk, Screening Intent, Benefits, Barriers, and Decision Conflict}

Appendix Figures 1 and 2 show changes in perceived risk, CRC screening intent, others from baseline (T0) to immediately post-intervention (T1). There were statistically significant increases in CRC screening intent, FIT intent, perceived benefits of FIT and colonoscopy, and significant decreases for decision conflict and perceived barriers for FIT and colonoscopy ( $p<$ 0.001) from T0 to T1 for both groups. There were no significant changes from T0 to T1 in perceived comparative risk, perceived personal risk, or colonoscopy intent.

As shown in Table 2, there were no group differences for changes in perceived comparative risk, CRC screening intent, colonoscopy intent, benefits or barriers for either colonoscopy or FIT, or decision conflict. Participants in the quantitative group had greater increases in FIT Intent $(p=0.007)$ and perceived personal risk $(p<.001)$ compared to the verbal group.

\subsection{Test Choice}

From T0 to T1, participants in both groups changed their test choice from 'Do Not Intend to be Screened' to one of the four screening options (colonoscopy, FIT, other, don't know/missing) (Appendix Table 2). As shown in Table 3, the proportion that made this change was higher in the quantitative group (85/176 [48\%]) compared to the verbal group (60/158 [38\%]; $p=0.02)$. A greater proportion of those in the quantitative group changed their test choice from non-FIT to FIT than the verbal group ( $29 \%$ vs $19 \%, p=0.005$ ).

\subsection{Uptake}

At 6-months, CRC screening uptake in the EHR for all participants was $29 \%$. FIT uptake was $11 \%$, and colonoscopy uptake was $19 \%$, with no difference in uptake between groups (Table 4). In the quantitative group, uptake of any CRC screening test was $29 \%$, FIT was $11 \%$, and colonoscopy was $19 \%$. In the verbal group, uptake of any CRC screening test was 30\%, FIT was $11 \%$, and colonoscopy was $20 \%$. 


\subsection{Effect of numeracy.}

Since we found the same substantive results for subjective and objective numeracy, we report the results for subjective numeracy only. Although there were some main effects of numeracy, there were no significant interactions between group and subjective numeracy for perceived risk, screening intent, benefits, barriers, or decision conflict, thus no evidence of moderation (Table 5).

\section{Discussion and Conclusion:}

\subsection{Discussion}

This study found that including quantitative information in a decision aid significantly increased intent to undergo FIT but not colonoscopy for screening and increased perceived CRC risk but not comparative risk in patients eligible for screening. Quantitative information had no impact on either uptake of screening or type of test at six months, and numeracy did not moderate the effect of quantitative information on any outcome. Both decision aids increased intent to undergo screening and reduced decision conflict, in pre- to post-testing.

Together, these findings help address concerns that quantitative information may have significant negative effects for patients overall, or for patients with limited numeracy skills. At the same time, the findings show relatively limited impacts of including quantitative information and leave questions unanswered about whether such information should be included in all decision aids. Since the study compared only one way of framing quantitative and verbal information about CRC screening, it cannot assess the impact of other methods of framing, or the impact of quantitative information on other medical decisions.

The only previous randomized trial that we are aware of that compared decision aids that differed only in their inclusion of quantitative information was a pilot study we conducted. In our study, 223 patients who were due for CRC screening were randomized to view four different decision aids, two that included quantitative information and two that did not [22]. Findings in the current study extend those of our earlier study but differ in certain ways, which we discuss here. 
One concern about disclosing the specific baseline risk for a cancer in a decision aid has been that it would lower people's perception of their risk which would lead to reduced intent and uptake of screening [10-12]. Another concern has been that disclosing the specific magnitude of absolute risk reduction provided by screening would reduce perceived benefit and, subsequently, reduce intent and uptake $[10,11]$. The current study does not support either of these concerns. While the change in perceived risk from T0 to T1 was significantly different for the two groups $(p=.007)$, the changes were relatively small $(+0.08$ in the quantitative group and -0.08 in the verbal group, on a four-point scale) and, thus, have questionable clinical significance. In our pilot study, individuals who viewed the quantitative information also had a small increase in perceived risk (+0.15 on a seven-point scale). Changes in perceived benefit of colonoscopy or FIT did not differ between groups.

The quantitative decision aid may have increased perceived risk, in part, by disclosing frequencies over a lifetime rather than a shorter time period, such as 5 or 10 years. Incidence and mortality from cancer and the magnitude of absolute risk reduction provided by screening is higher over a lifetime than over shorter periods.

Previous studies found that providing quantitative estimates of baseline risk of cancer leads to lower perceived risk, perhaps because people started with higher estimates of their risk. When told their baseline risk of getting breast cancer in their lifetime (approximately 13\% on average), women in a previous study had reduced perceived risk, in part since they estimated their risk beforehand as much higher (25\% or more in many cases) [32]. In another study, perceived risk of getting an upset stomach as a reaction to a medication was lower after the numeric frequency was disclosed $(14,000$ per 100,000$)$, than when it was described as "very common" [33]. In that case, perceived risk may have been lower after viewing the numbers since the term "very common" was associated by many subjects with a higher probability than $14 \%$. In our study, in contrast, the quantitative information presented in our decision aid regarding incidence and mortality of CRC may have generated an impression of these risks that was similar to the ones subjects developed when viewing the verbal decision aid.

Viewing either the quantitative or verbal aid increased intent to undergo FIT, measured either as a response to a five-point Likert scale ("FIT Intent") or as planned screening behavior 
("Test choice"). The increase was greater for both outcomes in the quantitative group than in the verbal group. Further, the changes in intent were clinically significant: the percent of patients choosing FIT as their test choice increased from T0 to T1 from $12 \%$ to $24 \%$ in the verbal group and from $11 \%$ to $34 \%$ in the quantitative group. These results match and extend findings from our pilot study, where mean FIT intent increased from T0 to T1 in both groups but the increase was significantly larger in the quantitative arm [22]. In the current study, the increase in selection of FIT as test choice resulted in an increase in intention to be screened overall that may be considered clinically significant (10\% difference). The higher test choice of FIT at T1 and of being screened overall in the quantitative arm, however, was not reflected in an increased uptake of FIT or of screening at 6 months.

Viewing either decision aid resulted in a significant increase in patients' intent to have FIT in part since many patients eligible for CRC screening do not know about alternative tests because many physicians offer only colonoscopy [34-36]. Our decision aids explain that stool testing is an approved alternative to colonoscopy, allowing patients to choose this non-invasive approach. The quantitative decision aid may have resulted in a larger increase in FIT intent than the verbal decision aid because the numbers presented showed that the risk reduction provided by colonoscopy and FIT is similar: according to a leading model on which we based our presentation (SimCRC), colonoscopy reduces CRC mortality from 30 per 1000 to 4.6 per 1000, FIT reduces it to 6 per 1000 [37].

As mentioned previously, there is concern that disclosing quantitative information about baseline risk in a decision aid for screening would decrease perceived risk, and thus decrease uptake [10-12]. In this situation, there would be difficult questions about whether the goals of disclosure before screening should prioritize improved understanding (respecting individual autonomy) or increasing uptake of screening (improved health outcomes) [13], and whether the decrease in uptake reflected the action of heuristics or biases rather than patients' informed preferences. The current study found no decrease in uptake. Our pilot study found that patients who viewed the quantitative decision aid had a significantly higher uptake of screening at six months than those who viewed the verbal decision aid [22], and we have no clear explanation for this difference in the studies. 
Our study has several notable strengths including that: 1) it was a randomized, controlled trial with a large sample size, fully powered for our primary outcomes; 2) patients were recruited from multiple clinics and were diverse in terms of race, income, and education; and 3) screening outcomes were measured using the EHR. The main limitations are that it recruited only within a single city and surrounding area, and it was not powered for several secondary outcomes or for numeracy-moderating effects. Although we measured knowledge, we will report those results, along with other measures of decision quality, subsequently.

Finally, the study outcomes could have been impacted by the framing of words and numbers presented in the decision aids, a limitation that applies to any study involving decision aids. As mentioned above, the increase in perceived risk seen with the quantitative decision aid may have been the result, at least in part, of the team's decision to describe risk and risk reduction over a lifetime, rather than a shorter time period, such as 10 years. The magnitudes of predicted risk and risk reduction over a lifetime are larger and potentially more impressive than over shorter time frames. As another example, in keeping with recommendations, the decision aids described the sensitivity of a single application of FIT and of colonoscopy for CRC, using a frequency and icon graph in the quantitative arm and words in the verbal arm. It is possible that viewers could overestimate the importance of a difference in sensitivity. For many patients, there may be no negative consequence of FIT failing to identify a cancer or polyp on a single application, since many polyps do not progress to cancer and many polyps or cancers will be identified on later annual applications before they have progressed. The decision aids included an explanation of why a missed polyp or cancer might not have a negative effect. Future research should further study the impact of message framing in decision aids, building on the extensive body of research on framing [38].

\subsection{Conclusion}

In conclusion, this study showed that including quantitative information in a decision aid regarding CRC screening had significant, if moderate, effects on patient perceptions and intent to undergo screening, specifically intent to undergo FIT. The study did not show negative impacts on either intention or uptake of screening, and did not find large differences among 
patients with high and low numeracy. Additional studies will be needed to determine the impact of other sorts of quantitative information, potentially framed in other ways, in decision aids.

\subsection{Practice Implications}

This study is the first adequately powered, randomized, controlled trial of the impact of quantitative information in a decision aid. The findings provide some support for recommendations that decision aids should provide patients with quantitative information about risks and benefits of available options. First, we did not find that quantitative information had negative consequences such as reducing uptake or negatively impacting decision-making of lower numeracy patients. Second, we found that quantitative information had the clinically significant impact of increasing the percentage of patients selecting FIT as their preferred test.

At the same time, these findings leave open the possibility that quantitative information should be an option for patients to view rather than a required part of decision aids. Further discussion of the place of quantitative information in decision aids will need to take these findings into account.

\section{Role of funding source:}

This trial was funded by the Patient-Centered Outcomes Research Institute (PCORI). The funding source had no role in the design, conduct, or analysis of the study.

\section{Conflict of interest}

The authors declare that they have no conflict of interest.

\section{Author contribution}

PHS, TFI, SMP, KKS, and SMR contributed to the study concept and design. KKS participated in acquisition of data. PHS, SMP, and SA analyzed and interpreted the data. All authors participated in drafting, revising, and approving the final manuscript. 


\section{Acknowledgments:}

Research reported in this manuscript was funded through a Patient-Centered Outcomes Research Institute (PCORI) Award (CDR-1403-11040). The views, statements, and opinions in this manuscript area solely the responsibility of the authors and do not necessarily represent the views of the Patient-Centered Outcomes Research Institute (PCORI), its Board of Governors or Methodology Committee. The authors wish to thank the following persons for their contributions to the successful completion of this study: our patient advisory boards who provided insightful and valuable help on all study materials; our community advisory board for their feedback on the decision aids; Evgenia Teal and Stan Taylor for electronic health record analysis and data management; Paul Muriello, Wendy Forest, Shivangi Gohil, Lauren Ford, Sabrina Cordon, Ariane Thomas, and Amy Price for their recruitment efforts, intervention delivery and data collection throughout the project; Brian Zikmund-Fisher, PhD, for assistance on the design of the decision aids; the leadership and staff of our affiliated health systems for providing access to their patients and clinic space; and all our study participants. 


\section{References:}

[1] G. Elwyn, A. O'Connor, D. Stacey, R. Volk, A. Edwards, A. Coulter, R. Thomson, A. Barratt, M. Barry, S. Bernstein, P. Butow, A. Clarke, V. Entwistle, D. Feldman-Stewart, M. HolmesRovner, H. Llewellyn-Thomas, N. Moumjid, A. Mulley, C. Ruland, K. Sepucha, A. Sykes, T. Whelan, C. The International Patient Decision Aids Standards, Developing a quality criteria framework for patient decision aids: online international Delphi consensus process, BMJ 333(7565) (2006) 417.

[2] L. Trevena, B. Zikmund-Fisher, A. Edwards, W. Gaissmaier, M. Galesic, P. Han, J. King, M. Lawson, S. Linder, I. Lipkus, E. Ozanne, E. Peters, D. Timmermans, S. Woloshin, Presenting probabilities, in: R. Volk, H. Llewellyn-Thomas (Eds.) 2012 Update of the International Patient Decision Aids Standards (IPDAS) Collaboration's Background Document. Chapter C. , 2012.

[3] J. Paling, Strategies to help patients understand risks, BMJ 327(7417) (2003) 745-8.

[4] G. Gigerenzer, A. Edwards, Simple tools for understanding risks: from innumeracy to insight, BMJ 327(7417) (2003) 741-744.

[5] M. Kutner, E. Greenberg, Y. Jin, C. Paulsen, The health literacy of America's adults: Results from the 2003 National Assessment of Adult Literacy, in: U.S.D.o. Education (Ed.) National Center for Education Statistics, Washington, DC, 2006.

[6] NCES, National Assessment of Adult Literacy (NAAL): Key findings: Demographics: Overall, 2003. http://nces.ed.gov/naal/kf_demographics.asp. (Accessed April 10 2013). 
[7] D. Stacey, F. Legare, K. Lewis, M.J. Barry, C.L. Bennett, K.B. Eden, M. Holmes-Rovner, H. Llewellyn-Thomas, A. Lyddiatt, R. Thomson, L. Trevena, Decision aids for people facing health treatment or screening decisions, Cochrane Database Syst Rev 4 (2017) CD001431.

[8] J.A. Shepperd, E.A. Waters, N.D. Weinstein, W.M.P. Klein, A Primer on Unrealistic Optimism, Current Directions in Psychological Science 24(3) (2015) 232-237.

[9] N.D. Weinstein, Unrealistic optimism about future life events, Journal of Personality and Social Psychology 39(5) (1980) 806-820.

[10] P.H. Schwartz, Questioning the quantitative imperative: decision aids, prevention, and the ethics of disclosure, Hastings Cent Rep 41(2) (2011) 30-9.

[11] B.J. Zikmund-Fisher, The right tool is what they need, not what we have: a taxonomy of appropriate levels of precision in patient risk communication, Med Care Res Rev 70 (1 Suppl) (2013) 37S-49S.

[12] H. McDonald, C. Charles, A. Gafni, Assessing the conceptual clarity and evidence base of quality criteria/standards developed for evaluating decision aids, Health Expectations 17(2) (2014) 232-243.

[13] A.E. Raffle, Information about screening: Is it to achieve high uptake or to ensure informed choice?, Health Expectations 4(2) (2001) 92-98.

[14] L.J. Trevena, B.J. Zikmund-Fisher, A. Edwards, W. Gaissmaier, M. Galesic, P.K. Han, J. King, M.L. Lawson, S.K. Linder, I. Lipkus, E. Ozanne, E. Peters, D. Timmermans, S. Woloshin, Presenting quantitative information about decision outcomes: a risk communication primer for patient decision aid developers, BMC Med Inform Decis Mak 13 Suppl 2 (2013) S7. 
[15] U.S.P.S.T. Force, K. Bibbins-Domingo, D.C. Grossman, S.J. Curry, K.W. Davidson, J.W. Epling, Jr., F.A.R. Garcia, M.W. Gillman, D.M. Harper, A.R. Kemper, A.H. Krist, A.E. Kurth, C.S. Landefeld, C.M. Mangione, D.K. Owens, W.R. Phillips, M.G. Phipps, M.P. Pignone, A.L. Siu, Screening for Colorectal Cancer: US Preventive Services Task Force Recommendation Statement, JAMA 315(23) (2016) 2564-2575.

[16] D.K. Rex, C.R. Boland, J.A. Dominitz, F.M. Giardiello, D.A. Johnson, T. Kaltenbach, T.R. Levin, D. Lieberman, D.J. Robertson, Colorectal cancer screening: Recommendations for physicians and patients from the U.S. Multi-Society Task Force on Colorectal Cancer, Gastroenterology 153(1) (2017) 307-323.

[17] C.N. Klabunde, D.A. Joseph, J.B. King, A. White, M. Plescia, Vital Signs: Colorectal cancer screening test use - United States, 2012, Morbidity and Mortality Weekly Report 62(44) (2013) 881-888.

[18] J.S. Lin, M.A. Piper, L.A. Perdue, C.M. Rutter, E.M. Webber, E. O'Connor, N. Smith, E.P. Whitlock, Screening for Colorectal Cancer: Updated Evidence Report and Systematic Review for the US Preventive Services Task Force, JAMA 315(23) (2016) 2576-94.

[19] P.A. Harris, R. Taylor, R. Thielke, J. Payne, N. Gonzalez, J.G. Conde, Research electronic data capture (REDCap)-A metadata-driven methodology and workflow process for providing translational research informatics support, Journal of Biomedical Informatics 42(2) (2009) $377-381$.

[20] A.C. Society, Get tested for colon cancer. Here's how., American Cancer Society, Inc., 2008. [21] I.D.A.S.I. Collaboration, International Decision Aid Standards (IPDAS) Collaboration Resources, 2012. http://ipdas.ohri.ca/resources.html. (Accessed April 10 2013). 
[22] P.H. Schwartz, S.M. Perkins, K.K. Schmidt, P.F. Muriello, S. Althouse, S.M. Rawl, Providing quantitative information and a nudge to undergo stool testing in a colorectal cancer screening decision aid: A randomized clinical trial, Med Decis Making 37(6) (2017) 688-702.

[23] S. Rawl, V. Champion, U. Menon, P.J. Loehrer, G.H. Vance, C.S. Skinner, Validation of scales to measure benefits of and barriers to colorectal cancer screening, Journal of Psychosocial Oncology 19(3/4) (2001) 47-63.

[24] A.M. O'Connor, User Manual - Decision Conflict Scale, 2005.

http://decisionaid.ohri.ca/docs/develop/User_Manuals/UM_Decisional_Conflict.pdf. (Accessed April 10 2013).

[25] A. Fagerlin, B.J. Zikmund-Fisher, P.A. Ubel, A. Jankovic, H.A. Derry, D.M. Smith, Measuring numeracy without a math test: development of the Subjective Numeracy Scale, Medical Decision Making 27(5) (2007) 672-80.

[26] B.J. Zikmund-Fisher, D.M. Smith, P.A. Ubel, A. Fagerlin, Validation of the Subjective Numeracy Scale: effects of low numeracy on comprehension of risk communications and utility elicitations, Med Decis Making 27(5) (2007) 663-71.

[27] M.M. Schapira, C.M. Walker, K.J. Cappaert, P.S. Ganschow, K.E. Fletcher, E.L. McGinley, S. Del Pozo, C. Schauer, S. Tarima, E.A. Jacobs, The Numeracy Understanding in Medicine Instrument: A measure of health numeracy developed using item response theory, Medical Decision Making 32(6) (2012) 851-865.

[28] M.M. Schapira, C.M. Walker, T. Miller, K.E. Fletcher, P.S. Ganschow, E.A. Jacobs, D. Imbert, M. O'Connell, J.M. Neuner, Development and validation of the numeracy understanding in Medicine Instrument short form, J Health Commun 19 Suppl 2 (2014) 240-53. 
[29] L.D. Chew, K.A. Bradley, E.J. Boyko, Brief questions to identify patients with inadequate health literacy, Family medicine 36(8) (2004) 588-594.

[30] E. Demidenko, Sample size and optimal design for logistic regression with binary interaction, Stat Med 27(1) (2008) 36-46.

[31] B.C. Kahan, T.P. Morris, Improper analysis of trials randomised using stratified blocks or minimisation, Stat Med 31(4) (2012) 328-340.

[32] A. Fagerlin, B.J. Zikmund-Fisher, P.A. Ubel, How making a risk estimate can change the feel of that risk: shifting attitudes toward breast cancer risk in a general public survey, Patient Education \& Counseling 57(3) (2005) 294-9.

[33] E. Peters, P.S. Hart, M. Tusler, L. Fraenkel, Numbers matter to informed patient choices: a randomized design across age and numeracy levels, Med Decis Making 34(4) (2014) 430 -

42.

[34] A. McQueen, L.K. Bartholomew, A.J. Greisinger, G.G. Medina, S.T. Hawley, P. Haidet, J.L. Bettencourt, N.K. Shokar, B.S. Ling, S.W. Vernon, Behind closed doors: Physician-patient discussions about colorectal cancer screening, J Gen Intern Med 24(11) (2009) 1228-35.

[35] B.S. Ling, J.M. Trauth, M.J. Fine, M.K. Mor, A. Resnick, C.H. Braddock, S. Bereknyei, J.L. Weissfeld, R.E. Schoen, E.M. Ricci, J. Whittle, Informed decision-making and colorectal cancer screening: is it occurring in primary care?, Med Care 46(9 Suppl 1) (2008) S23-9.

[36] P.H. Schwartz, E. Edenberg, P.R. Barrett, S.M. Perkins, E.M. Meslin, T.F. Imperiale, Patient understanding of benefits, risks, and alternatives to screening colonoscopy, Family medicine 45(2) (2013) 83-9. 
[37] A.G. Zauber, I. Lansdorp-Vogelaar, A.B. Knudsen, J. Wilschut, M. van Ballegooijen, K.M. Kuntz, Evaluating test strategies for colorectal cancer screening: a decision analysis for the U.S. Preventive Services Task Force, Ann Intern Med 149(9) (2008) 659-69.

[38] A. Edwards, G. Elwyn, J. Covey, E. Matthews, R. Pill, Presenting risk information--a review of the effects of "framing" and other manipulations on patient outcomes, Journal of Health Communication 6(1) (2001) 61-82. 
Figure 1 Study flow diagram

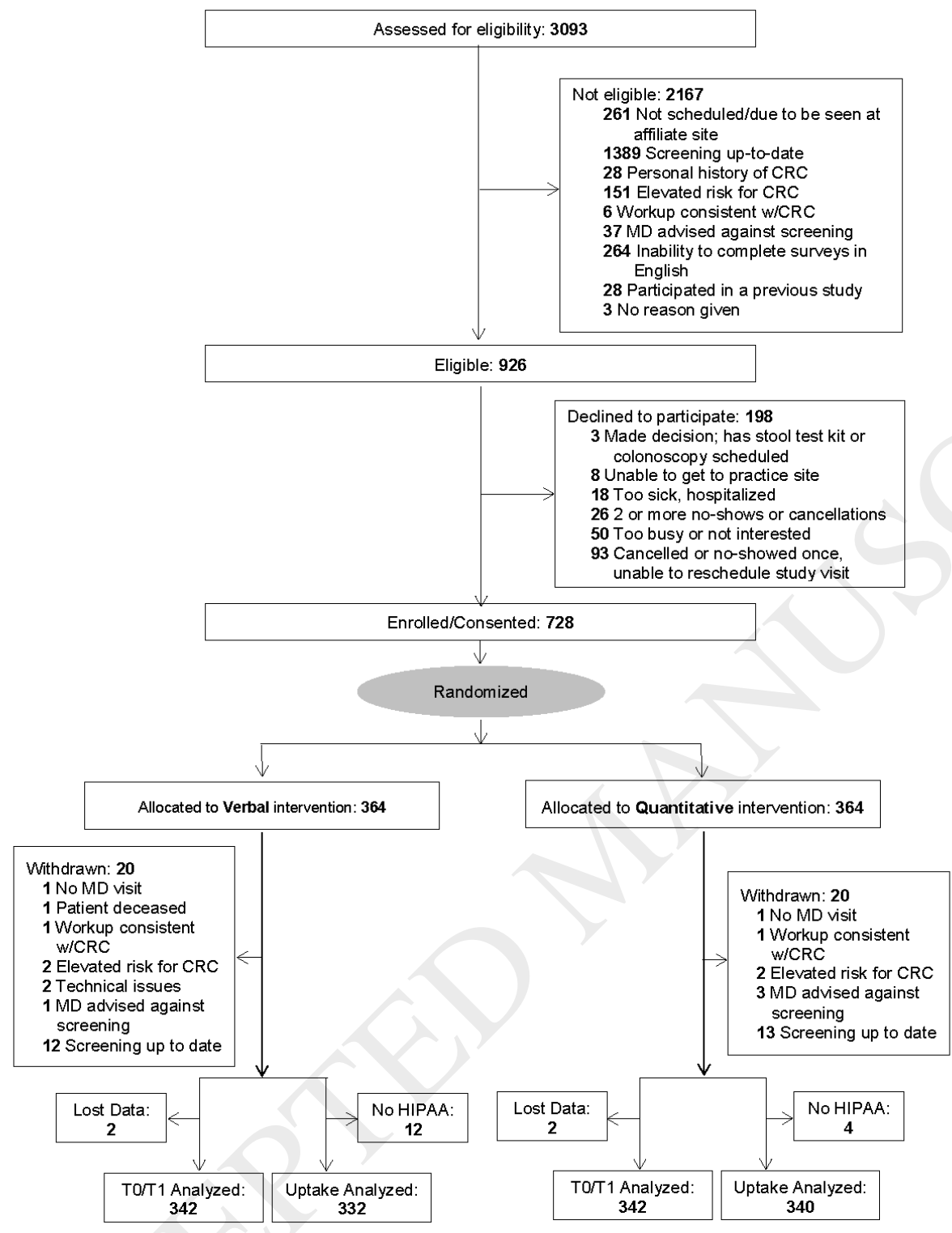


Table 1: Demographics by Group (Mean [SD] or $\mathrm{n}[\%]$ )

\begin{tabular}{|c|c|c|c|c|}
\hline Category & Value & $\begin{array}{l}\text { Verbal } \\
(\mathrm{N}=344)\end{array}$ & $\begin{array}{l}\text { Quantitative } \\
(\mathrm{N}=344)\end{array}$ & $\begin{array}{l}\mathrm{p} \text { - } \\
\text { value* }\end{array}$ \\
\hline \multirow{2}{*}{ Site } & Eskenazi & $96(28 \%)$ & 93 (27\%) & \multirow[t]{2}{*}{0.80} \\
\hline & IU Health & 248 (72\%) & 251 (73\%) & \\
\hline Age & Mean (SD) & 58.71 (6.49) & $58.83(6.66)$ & 0.81 \\
\hline \multirow{2}{*}{ Age - Categorical } & $<=65 \mathrm{y} / \mathrm{o}$ & $288(84 \%)$ & $283(82 \%)$ & \multirow[t]{2}{*}{0.61} \\
\hline & $>65$ y/o & $56(16 \%)$ & $61(18 \%)$ & \\
\hline \multirow{2}{*}{ Gender } & Female & $206(60 \%)$ & $198(58 \%)$ & \multirow[t]{2}{*}{0.54} \\
\hline & Male & $138(40 \%)$ & 146 (42\%) & \\
\hline \multirow{8}{*}{ Race } & $\begin{array}{l}\text { American Indian or Alaskan } \\
\text { Native }\end{array}$ & $1(0 \%)$ & $1(0 \%)$ & \multirow[t]{8}{*}{0.106} \\
\hline & Asian & $3(1 \%)$ & $4(1 \%)$ & \\
\hline & Black or African American & $98(28 \%)$ & $86(25 \%)$ & \\
\hline & Missing & $12(3 \%)$ & $10(3 \%)$ & \\
\hline & 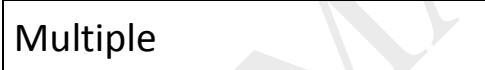 & $16(5 \%)$ & $5(1 \%)$ & \\
\hline & $\begin{array}{l}\text { Native Hawaiian or Pacific } \\
\text { Islander }\end{array}$ & $1(0 \%)$ & $1(0 \%)$ & \\
\hline & Other race & $8(2 \%)$ & $5(1 \%)$ & \\
\hline & White & $205(60 \%)$ & $232(67 \%)$ & \\
\hline \multirow{4}{*}{ Ethnicity - Hispanic/Latino } & Yes & $12(3 \%)$ & $5(1 \%)$ & \multirow[t]{4}{*}{0.112} \\
\hline & No & 317 (92\%) & 329 (96\%) & \\
\hline & Do not know & $4(1 \%)$ & $1(0 \%)$ & \\
\hline & Missing & $11(3 \%)$ & $9(3 \%)$ & \\
\hline \multirow{6}{*}{ Education } & Less than high school & $25(7 \%)$ & $15(4 \%)$ & \multirow[t]{6}{*}{0.38} \\
\hline & High school graduate/GED & 75 (22\%) & $89(26 \%)$ & \\
\hline & $\begin{array}{l}\text { Some college/technical } \\
\text { school/trade school }\end{array}$ & $92(27 \%)$ & $80(23 \%)$ & \\
\hline & Associate's degree school & $35(10 \%)$ & $31(9 \%)$ & \\
\hline & Bachelor's degree & $58(17 \%)$ & $68(20 \%)$ & \\
\hline & $\begin{array}{l}\text { Professional or graduate } \\
\text { degree }\end{array}$ & $44(13 \%)$ & $51(15 \%)$ & \\
\hline
\end{tabular}




\begin{tabular}{|c|c|c|c|c|}
\hline Category & Value & $\begin{array}{l}\text { Verbal } \\
(\mathrm{N}=344)\end{array}$ & $\begin{array}{l}\text { Quantitative } \\
(\mathrm{N}=344)\end{array}$ & $\begin{array}{l}\mathrm{p} \text { - } \\
\text { value* }\end{array}$ \\
\hline & Don't Know & $2(1 \%)$ & $1(0 \%)$ & \\
\hline & Missing & $13(4 \%)$ & $9(3 \%)$ & \\
\hline \multirow{6}{*}{ Relationship } & Single & 71 (21\%) & 75 (22\%) & \multirow[t]{6}{*}{0.21} \\
\hline & Married/living with partner & $170(49 \%)$ & $168(49 \%)$ & \\
\hline & Separated & $12(3 \%)$ & $10(3 \%)$ & \\
\hline & Divorced & $61(18 \%)$ & $73(21 \%)$ & \\
\hline & Widowed & $19(6 \%)$ & $8(2 \%)$ & \\
\hline & Missing & $11(3 \%)$ & $10(3 \%)$ & \\
\hline \multirow{3}{*}{ Employed? } & Yes & $158(46 \%)$ & $188(55 \%)$ & \multirow[t]{3}{*}{0.037} \\
\hline & No & $170(49 \%)$ & $146(42 \%)$ & \\
\hline & Missing & $16(5 \%)$ & $10(3 \%)$ & \\
\hline \multirow{3}{*}{ Health Insurance? } & Yes & 315 (92\%) & 317 (92\%) & \multirow[t]{3}{*}{0.49} \\
\hline & No & $13(4 \%)$ & $17(5 \%)$ & \\
\hline & 2010 & $16(5 \%)$ & $10(3 \%)$ & \\
\hline \multirow{4}{*}{ Income Level Subjective } & Are comfortable & $129(38 \%)$ & $145(42 \%)$ & \multirow[t]{4}{*}{0.113} \\
\hline & $\begin{array}{l}\text { Have just enough to make } \\
\text { ends meet }\end{array}$ & $117(34 \%)$ & $125(36 \%)$ & \\
\hline & $\begin{array}{l}\text { Do NOT have enough to } \\
\text { make ends meet }\end{array}$ & $80(23 \%)$ & $59(17 \%)$ & \\
\hline & Missing & $18(5 \%)$ & $15(4 \%)$ & \\
\hline \multirow{3}{*}{ Ever heard of FIT? } & Yes & $234(68 \%)$ & 242 (70\%) & \multirow[t]{3}{*}{0.86} \\
\hline & No & 78 (23\%) & $78(23 \%)$ & \\
\hline & Missing & 32 (9\%) & $24(7 \%)$ & \\
\hline \multirow{3}{*}{ Ever heard of Colonoscopy? } & Yes & 295 (86\%) & 312 (91\%) & \multirow[t]{3}{*}{0.094} \\
\hline & No & $17(5 \%)$ & $9(3 \%)$ & \\
\hline & Missing & $32(9 \%)$ & $23(7 \%)$ & \\
\hline \multirow{3}{*}{$\begin{array}{l}\text { Doctor ever recommend } \\
\text { colon test? }\end{array}$} & Yes & 190 (55\%) & 206 (60\%) & \multirow[t]{3}{*}{0.64} \\
\hline & No & 105 (31\%) & 105 (31\%) & \\
\hline & Do not know & $16(5 \%)$ & $10(3 \%)$ & \\
\hline
\end{tabular}




\begin{tabular}{|c|c|c|c|c|}
\hline Category & Value & $\begin{array}{l}\text { Verbal } \\
(\mathrm{N}=344)\end{array}$ & $\begin{array}{l}\text { Quantitative } \\
(\mathrm{N}=344)\end{array}$ & $\begin{array}{l}p- \\
\text { value* }\end{array}$ \\
\hline & Missing & $33(10 \%)$ & $23(7 \%)$ & \\
\hline \multirow{4}{*}{$\begin{array}{l}\text { Doctor ever recommend } \\
\text { colonoscopy? }\end{array}$} & Yes & $172(50 \%)$ & $179(52 \%)$ & \multirow[t]{4}{*}{0.88} \\
\hline & No & 121 (35\%) & $129(38 \%)$ & \\
\hline & Do not know & $16(5 \%)$ & $13(4 \%)$ & \\
\hline & Missing & $35(10 \%)$ & $23(7 \%)$ & \\
\hline \multirow{4}{*}{$\begin{array}{l}\text { Doctor ever recommend FIT } \\
\text { test? }\end{array}$} & Yes & $88(26 \%)$ & $101(29 \%)$ & \multirow[t]{4}{*}{0.39} \\
\hline & No & 200 (58\%) & $197(57 \%)$ & \\
\hline & Do not know & $21(6 \%)$ & $21(6 \%)$ & \\
\hline & Missing & 35 (10\%) & $25(7 \%)$ & \\
\hline
\end{tabular}

${ }^{*} p$-value from t-test, Chi-Square, or Fisher's Exact Test, where appropriate. Missing and Do not know were not included in analysis. 
Table 2: Between-Group Differences in Change in Perceived Risk, Intent, Benefits, Barriers, and Decision Conflict

\begin{tabular}{|c|c|c|c|c|}
\hline Variable & Group & $\begin{array}{l}\text { Change (T1 - T0) } \\
\text { N, Mean (SD) }\end{array}$ & $\begin{array}{l}\text { Intervention Effect } \\
\text { Estimate }(95 \% \mathrm{Cl}) * *\end{array}$ & p-value* \\
\hline \multirow{2}{*}{ Perceived Comparative Risk } & Verbal & $217,-0.04(0.45)$ & \multirow[t]{2}{*}{$0.06(-0.02,0.14)$} & \multirow[t]{2}{*}{0.173} \\
\hline & Quantitative & $232,0.05(0.52)$ & & \\
\hline \multirow{2}{*}{ Perceived Personal Risk } & Verbal & $333,-0.08(0.70)$ & \multirow[t]{2}{*}{$0.16(0.07,0.26)$} & \multirow[t]{2}{*}{$<0.001$} \\
\hline & Quantitative & $336,0.08(0.81)$ & & \\
\hline \multirow{2}{*}{ CRC Screening Intent } & Verbal & $342,0.37(0.84)$ & \multirow[t]{2}{*}{$0.09(-0.03,0.20)$} & \multirow[t]{2}{*}{0.142} \\
\hline & Quantitative & $342,0.47(0.84)$ & & \\
\hline \multirow{2}{*}{ Colonoscopy Intent } & Verbal & $341,0.03(0.81)$ & \multirow{2}{*}{$0.03(-0.09,0.14)$} & \multirow[t]{2}{*}{0.66} \\
\hline & Quantitative & $338,0.06(0.80)$ & & \\
\hline \multirow{2}{*}{ FIT Intent } & Verbal & $341,0.26(1.13)$ & \multirow[t]{2}{*}{$0.22(0.06,0.37)$} & \multirow[t]{2}{*}{0.007} \\
\hline & Quantitative & $338,0.46(1.09)$ & & \\
\hline \multirow{2}{*}{ Colonoscopy Benefits } & Verbal & $324,0.44(0.62)$ & \multirow[t]{2}{*}{$0.03(-0.05,0.11)$} & \multirow[t]{2}{*}{0.47} \\
\hline & Quantitative & $332,0.47(0.62)$ & & \\
\hline \multirow{2}{*}{ FIT Benefits } & Verbal & $320,0.44(0.76)$ & \multirow[t]{2}{*}{$0.07(-0.02,0.17)$} & \multirow[t]{2}{*}{0.138} \\
\hline & Quantitative & $330,0.52(0.73)$ & & \\
\hline \multirow{2}{*}{ Colonoscopy Barriers } & Verbal & $322,-0.18(0.47)$ & \multirow[t]{2}{*}{$0.05(-0.02,0.12)$} & \multirow[t]{2}{*}{0.149} \\
\hline & Quantitative & $330,-0.13(0.45)$ & & \\
\hline \multirow{2}{*}{ FIT Barriers } & Verbal & $321,-0.18(0.55)$ & \multirow[t]{2}{*}{$-0.01(-0.09,0.07)$} & \multirow[t]{2}{*}{0.74} \\
\hline & Quantitative & $327,-0.21(0.54)$ & & \\
\hline \multirow{2}{*}{ Overall Decision Conflict Score } & Verbal & $316,-19.3(17.77)$ & \multirow[t]{2}{*}{$-0.12(-1.95,1.72)$} & \multirow[t]{2}{*}{0.90} \\
\hline & Quantitative & $326,-22.0(19.25)$ & & \\
\hline
\end{tabular}

*p-value for Group from the model: T1 outcome $=$ Group + T0 outcome + site + age + gender + employment

**the Verbal Group is the reference group 
Table 3: Change in Test Preference from T0 to T1 by Group, Overall and by Subjective Numeracy Level

\begin{tabular}{|c|c|c|c|c|c|c|}
\hline \multirow[b]{2}{*}{ Group } & \multicolumn{3}{|c|}{ Change from not Screen to Screen } & \multicolumn{3}{|c|}{ Change from not FIT to FIT } \\
\hline & Overall & $\begin{array}{c}\text { Low } \\
\text { Subjective } \\
\text { Numeracy }\end{array}$ & $\begin{array}{c}\text { High } \\
\text { Subjective } \\
\text { Numeracy }\end{array}$ & Overall & $\begin{array}{l}\text { Low } \\
\text { Subjective } \\
\text { Numeracy }\end{array}$ & $\begin{array}{c}\text { High } \\
\text { Subjective } \\
\text { Numeracy }\end{array}$ \\
\hline Verbal & $60 / 158(38 \%)$ & $34 / 77$ (44\%) & $25 / 79(32 \%)$ & $\begin{array}{l}56 / 301 \\
(19 \%)\end{array}$ & $31 / 147(21 \%)$ & $24 / 149(16 \%)$ \\
\hline Quantitative & $85 / 176(48 \%)$ & $40 / 86(47 \%)$ & $44 / 88(50 \%)$ & $\begin{array}{l}87 / 305 \\
(29 \%)\end{array}$ & $42 / 140(30 \%)$ & $45 / 161(28 \%)$ \\
\hline $\begin{array}{l}\text { Final Model } \\
\text { (Main Effects) } \\
\text { p-values }\end{array}$ & 0.022 & \multicolumn{2}{|c|}{$\begin{array}{l}\text { Arm: } 0.020^{*} \\
\text { Numeracy: } 0.61\end{array}$} & 0.005 & \multicolumn{2}{|c|}{$\begin{array}{l}\text { Arm: } 0.004^{*} \\
\text { Numeracy: } 0.48\end{array}$} \\
\hline
\end{tabular}

*All results are from the main effects model since the interaction Group*numeracy was not significant in any of the model 
Table 4: CRC Screening Uptake, Overall and by Group and Subjective Numeracy Level

\begin{tabular}{|c|c|c|c|c|c|}
\hline & Variable & $\begin{array}{l}\text { Verbal } \\
\text { n/N (\%) }\end{array}$ & $\begin{array}{c}\text { Quantitative } \\
\text { n/N (\%) }\end{array}$ & $\begin{array}{l}\text { Final Model } \\
\text { (Main Effects) } \\
\text { p-values* }\end{array}$ & Odds Ratio (95\% Cl) \\
\hline \multirow{3}{*}{ Overall } & $\begin{array}{l}\text { CRC } \\
\text { screening } \\
\text { uptake }\end{array}$ & 99/332 (29.8\%) & $99 / 340(29.1 \%)$ & 0.74 & $0.94(0.67,1.33)$ \\
\hline & FIT uptake & $36 / 332(10.8 \%)$ & $38 / 340(11.2 \%)$ & 0.96 & $1.01(0.62,1.67)$ \\
\hline & $\begin{array}{l}\text { Colonoscop } \\
\text { y uptake }\end{array}$ & 64/332 (19.3\%) & $63 / 340(18.5 \%)$ & 0.72 & $0.93(0.63,1.38)$ \\
\hline \multirow{3}{*}{$\begin{array}{l}\text { Below } \\
\text { Total } \\
\text { Subjective } \\
\text { Numeracy } \\
\text { Median }\end{array}$} & $\begin{array}{l}\text { CRC } \\
\text { screening } \\
\text { uptake }\end{array}$ & $43 / 167$ (25.6\%) & $34 / 158(21.5 \%)$ & $\begin{array}{l}\text { Group: } 0.70 \\
\text { Numeracy: } \\
0.031\end{array}$ & $\begin{array}{l}\text { Group: } 0.94 \text { (0.66, } \\
1.32) \\
\text { Numeracy: } 1.48 \text { (1.04, } \\
2.11)\end{array}$ \\
\hline & FIT uptake & $15 / 167$ (9.0\%) & $8 / 158(5.1 \%)$ & $\begin{array}{l}\text { Group: } 0.90 \\
\text { Numeracy: } \\
\mathbf{0 . 0 1 3}\end{array}$ & $\begin{array}{l}\text { Group: } 0.97 \text { (0.58, } \\
1.61) \\
\text { Numeracy: } 1.99 \text { (1.16, } \\
3.40)\end{array}$ \\
\hline & $\begin{array}{l}\text { Colonoscop } \\
\text { y uptake }\end{array}$ & $29 / 167$ (17.4\%) & $26 / 158(16.5 \%)$ & $\begin{array}{l}\text { Group: } 0.78 \\
\text { Numeracy: } 0.57\end{array}$ & $\begin{array}{l}\text { Group: } 0.95 \text { (0.63, } \\
1.41) \\
\text { Numeracy: } 1.13(0.75, \\
1.69)\end{array}$ \\
\hline \multirow{3}{*}{$\begin{array}{l}\text { Above } \\
\text { Total } \\
\text { Subjective } \\
\text { Numeracy } \\
\text { Median }\end{array}$} & $\begin{array}{l}\text { CRC } \\
\text { screening } \\
\text { uptake }\end{array}$ & $53 / 157(33.8 \%)$ & $63 / 175(36.0 \%)$ & & \\
\hline & FIT uptake & 20/157 (12.7\%) & 29/175 (16.6\%) & & \\
\hline & $\begin{array}{l}\text { Colonoscop } \\
\text { y uptake }\end{array}$ & $33 / 157$ (22.0\%) & $36 / 175(20.6 \%)$ & & \\
\hline
\end{tabular}

$\mathrm{n}=$ number screened; $\mathrm{N}=$ Total $\mathrm{N}$

*overall: p-value for Group from the model: Uptake=Group + site + age + gender + employment By numeracy: $p$-value for Group and numeracy from the model: Uptake $=$ Group + numeracy + site + age + gender + employment. All results are from the main effects model since the interaction Group*numeracy was not significant in any of the models. 
Table 5: Between-Group Differences in Change in Perceived Risk, Intent, Benefits, Barriers, and Decision Conflict by Subjective Numeracy (Above/Below the Median)

\begin{tabular}{|c|c|c|c|c|c|}
\hline Variable & $\begin{array}{l}\text { Subjective } \\
\text { Numeracy }\end{array}$ & Group & $\begin{array}{c}\text { Change (T1-T0) } \\
\mathrm{N}, \text { Mean (SD) }\end{array}$ & $\begin{array}{l}\text { Intervention Effect Estimate } \\
\qquad(95 \% \mathrm{Cl})^{* *}\end{array}$ & $\begin{array}{c}\text { Final Model } \\
\text { (Main Effects) } \\
\text { p-value* }\end{array}$ \\
\hline \multirow{4}{*}{$\begin{array}{l}\text { Perceived } \\
\text { Comparative } \\
\text { risk }\end{array}$} & \multirow{2}{*}{ Low } & Verbal & $94,0.00(0.46)$ & \multirow{4}{*}{$\begin{array}{l}\text { Group: } 0.06(-0.02,0.13) \\
\text { Numeracy: } 0.14(0.06,0.22)\end{array}$} & \multirow{4}{*}{$\begin{array}{l}\text { Group: } 0.169 \\
\text { Numeracy: } \mathbf{0 . 0 0 1}\end{array}$} \\
\hline & & Quantitative & $98,0.10(0.55)$ & & \\
\hline & \multirow{2}{*}{ High } & Verbal & $121,-0.07(0.44)$ & & \\
\hline & & Quantitative & $132,0.01(0.49)$ & & \\
\hline \multirow{4}{*}{$\begin{array}{l}\text { Perceived } \\
\text { Personal risk }\end{array}$} & \multirow{2}{*}{ Low } & Verbal & $169,-0.04(0.77)$ & \multirow{4}{*}{$\begin{array}{l}\text { Group: } 0.17(0.07,0.26) \\
\text { Numeracy: } 0.17(0.07,0.27)\end{array}$} & \multirow{4}{*}{$\begin{array}{l}\text { Group: }<0.001 \\
\text { Numeracy: }<0.001\end{array}$} \\
\hline & & Quantitative & $159,0.15(0.86)$ & & \\
\hline & \multirow{2}{*}{ High } & Verbal & $161,-0.14(0.63)$ & & \\
\hline & & Quantitative & $175,0.03(0.76)$ & & \\
\hline \multirow[t]{3}{*}{$\begin{array}{l}\text { CRC Screening } \\
\text { Intent }\end{array}$} & Low & $\begin{array}{r}\text { Verbal } \\
\text { Quantitative }\end{array}$ & $\begin{array}{ll}172, & 0.38(0.82) \\
160, & 0.48(0.88)\end{array}$ & \multirow[t]{3}{*}{$\begin{array}{l}\text { Group: } 0.09(-0.03,0.20) \\
\text { Numeracy: }-0.02(-0.14,0.10)\end{array}$} & \multirow[t]{3}{*}{$\begin{array}{l}\text { Group: } 0.137 \\
\text { Numeracy: } 0.70\end{array}$} \\
\hline & \multirow{2}{*}{ High } & Verbal & $164,0.36(0.88)$ & & \\
\hline & & Quantitative & $177,0.47(0.81)$ & & \\
\hline \multirow{4}{*}{$\begin{array}{l}\text { Colonoscopy } \\
\text { Intent }\end{array}$} & \multirow{2}{*}{ Low } & Verbal & $172,0.05(0.82)$ & \multirow{4}{*}{$\begin{array}{l}\text { Group: } 0.02(-0.10,0.14) \\
\text { Numeracy: } 0.08(-0.05,0.20)\end{array}$} & \multirow{4}{*}{$\begin{array}{l}\text { Group: } 0.74 \\
\text { Numeracy: } 0.23\end{array}$} \\
\hline & & Quantitative & $158,0.16(0.80)$ & & \\
\hline & \multirow{2}{*}{ High } & Verbal & $164,0.02(0.80)$ & & \\
\hline & & Quantitative & $176,-0.03(0.79)$ & & \\
\hline \multirow[t]{4}{*}{ FIT Intent } & \multirow{2}{*}{ Low } & Verbal & $172,0.21(1.18)$ & \multirow{4}{*}{$\begin{array}{l}\text { Group: } 0.21(0.05,0.36) \\
\text { Numeracy: }-0.03(-0.19,0.13)\end{array}$} & \multirow{4}{*}{$\begin{array}{l}\text { Group: } \mathbf{0 . 0 1 1} \\
\text { Numeracy: } 0.71\end{array}$} \\
\hline & & Quantitative & $158,0.49(1.13)$ & & \\
\hline & \multirow{2}{*}{ High } & Verbal & $164,0.34(1.03)$ & & \\
\hline & & Quantitative & $176,0.45(1.06)$ & & \\
\hline \multirow{4}{*}{$\begin{array}{l}\text { Colonoscopy } \\
\text { Benefits }\end{array}$} & \multirow{2}{*}{ Low } & Verbal & $162,0.40(0.62)$ & \multirow{4}{*}{$\begin{array}{l}\text { Group: } 0.03(-0.06,0.11) \\
\text { Numeracy: }-0.15(-0.24,0.07)\end{array}$} & \multirow{4}{*}{$\begin{array}{l}\text { Group: } 0.53 \\
\text { Numeracy: }<0.001\end{array}$} \\
\hline & & Quantitative & $156,0.39(0.60)$ & & \\
\hline & \multirow{2}{*}{ High } & Verbal & $161,0.49(0.61)$ & & \\
\hline & & Quantitative & $174,0.53(0.64)$ & & \\
\hline \multirow[t]{4}{*}{ FIT Benefits } & \multirow{2}{*}{ Low } & Verbal & $159,0.33(0.68)$ & Group: $0.07(-0.03,0.16)$ & Group: 0.172 \\
\hline & & Quantitative & $156,0.46(0.75)$ & Numeracy: -0.19 (-0.29, - & Numeracy: $<0.001$ \\
\hline & Hirh & Verbal & $160,0.56(0.81)$ & & \\
\hline & 115ா & Quantitative & $173,0.58(0.71)$ & & \\
\hline
\end{tabular}




\begin{tabular}{|c|c|c|c|c|c|}
\hline Variable & $\begin{array}{l}\text { Subjective } \\
\text { Numeracy }\end{array}$ & Group & $\begin{array}{l}\text { Change (T1-T0) } \\
\mathrm{N}, \text { Mean (SD) }\end{array}$ & $\begin{array}{l}\text { Intervention Effect Estimate } \\
\qquad(95 \% \mathrm{Cl})^{* *}\end{array}$ & $\begin{array}{c}\text { Final Model } \\
\text { (Main Effects) } \\
\text { p-value* }\end{array}$ \\
\hline \multirow{4}{*}{$\begin{array}{l}\text { Colonoscopy } \\
\text { Barriers }\end{array}$} & \multirow{2}{*}{ Low } & Verbal & $161,-0.16(0.46)$ & \multirow{4}{*}{$\begin{array}{l}\text { Group: } 0.05(-0.02,0.12) \\
\text { Numeracy: } 0.01(-0.06,0.08)\end{array}$} & \multirow{4}{*}{$\begin{array}{l}\text { Group: } 0.130 \\
\text { Numeracy: } 0.77\end{array}$} \\
\hline & & Quantitative & $155,-0.15(0.48)$ & & \\
\hline & \multirow{2}{*}{ High } & Verbal & $160,-0.19(0.48)$ & & \\
\hline & & Quantitative & $174,-0.10(0.42)$ & & \\
\hline \multirow[t]{4}{*}{ FIT Barriers } & \multirow{2}{*}{ Low } & Verbal & $160,-0.17(0.55)$ & \multirow{4}{*}{$\begin{array}{l}\text { Group: }-0.01(-0.09,0.07) \\
\text { Numeracy: } 0.10(0.02,0.19)\end{array}$} & \multirow{4}{*}{$\begin{array}{l}\text { Group: } 0.81 \\
\text { Numeracy: } \mathbf{0 . 0 1 4}\end{array}$} \\
\hline & & Quantitative & $155,-0.14(0.57)$ & & \\
\hline & \multirow{2}{*}{ High } & Verbal & $160,-0.20(0.55)$ & & \\
\hline & & Quantitative & $171,-0.27(0.50)$ & & \\
\hline \multirow{4}{*}{$\begin{array}{l}\text { Overall Conflict } \\
\text { Score }\end{array}$} & \multirow{2}{*}{ Low } & Verbal & $159,-18.0(17.80)$ & \multirow{4}{*}{$\begin{array}{l}\text { Arm: }-0.05(-1.87,1.76) \\
\text { Numeracy: } 3.66(1.79,5.53)\end{array}$} & \multirow{4}{*}{$\begin{array}{l}\text { Arm: } 0.95 \\
\text { Numeracy: }<\mathbf{0 . 0 0 1}\end{array}$} \\
\hline & & Quantitative & $154,-18.2$ (17.59) & & \\
\hline & \multirow{2}{*}{ High } & Verbal & $157,-20.6(17.71)$ & & \\
\hline & & Quantitative & $172,-25.3(20.08)$ & & \\
\hline
\end{tabular}

$*$ p-value from the model: T1 outcome $=$ arm + numeracy + T0 outcome + site + age + gender + employment. Only main effect models were used since arm*numeracy was not significant in any of the interaction models.

$* *$ the Verbal arm and High Numeracy were the reference groups. 